Article

\title{
Homelessness Pathways for Australian Single Mothers and Their Children: An Exploratory Study
}

\author{
Wayne Warburton ${ }^{1, *}\left(\mathbb{D}\right.$, Elizabeth Whittaker ${ }^{2}$ and Marina Papic ${ }^{3}$ \\ 1 Psychology Department, Macquarie University, Sydney, NSW 2109, Australia \\ 2 Department of Family and Community Services, Sydney 2000, Australia; \\ Elizabeth.Whittaker@facs.nsw.gov.au \\ 3 Kids' Early Learning, Blacktown City Council, Blacktown 2148, Australia; \\ marina.papic@blacktown.nsw.gov.au \\ * Correspondence: wayne.warburton@mq.edu.au; Tel.: +61-2-9850-8643
}

Received: 16 October 2017; Accepted: 27 February 2018; Published: 5 March 2018

\begin{abstract}
There is increasing concern about family homelessness. Homeless mothers and their children are one of society's most disadvantaged and at-risk populations. However, very little Australian research exploring mothers' views on their homelessness experiences exists. Using semi-structured interviews with 14 mothers and four agency staff, this study explored homeless Australian mothers' pathways into and out of homelessness, their specific needs and the services and supports that were (or would have been) most helpful. In this sample of single mothers and their children, early experiences of homelessness and domestic violence contributed most commonly to homelessness episodes. Almost immediate engagement with welfare agencies seemed to be protective against re-experiencing homelessness, however Australian restrictions on length of program involvement and limited housing options for mothers exiting homelessness programs, may place such mothers and their children at high risk of re-entering homelessness. Younger mothers had greater needs and benefited most from personalised one-on-one support that addressed key parenting and life skills. The implications of these findings are considered in relation to service delivery to this vulnerable group and avenues for future research are noted.
\end{abstract}

Keywords: homeless; mothers; children; service providers; qualitative research; Australia

\section{Introduction}

In 2007, Minnery and Greenhalgh reported that research had revealed a 'new homeless' (families, women and children) that were growing in significance in Australia, the US and Europe [1]. This was formally recognised in Australia in 2008, when families experiencing homelessness were identified as a priority group by the Australian government [2], a focus that continued well into the ensuing decade [3]. Such families are known to be particularly vulnerable [2] and research has found that Australian homeless parents and their children face considerable challenges to their wellbeing $[4,5]$. Despite recognition of this growing issue, national figures show that family homelessness rates have continued to remain high in Australia, with Supported Accommodation Assistance Program (SAAP) welfare services supporting over 67,000 families in 2013-2014 [6] and Specialist Homelessness Services (SHS) assisting 114,757 clients in 2016-2017. Forty percent of SHS clients were accessing services due to domestic and family violence, with $48 \%$ of these being single mothers [7].

International trends also reveal an increase in homeless families in some regions. For example, statistics from the US show that homeless families now comprise over one third of the homeless population [8] and almost 2.5 million children (one in thirty) are homeless [9]. In Europe, homeless families are the fastest growing section of the homeless population [10]. Within the population of homeless families appears to be a disproportional increase in ethnic minorities, particularly those who 
have recently immigrated due to conflict or poverty [11,12]. In recent decades, there has also been an increased risk of female-headed families becoming homeless due to domestic violence (through fleeing violent partners) or economic hardship (through the inability to afford stable accommodation) $[3,13,14]$. Family homelessness has become more prevalent and pervasive among poor and low-income families [15]. International research has identified distinct differences among homeless families compared to other homeless groups, suggesting that tailored support and interventions may be required to address their specific housing and service delivery needs [16].

These trends are important because it is now well established that homeless families face substantial problems. Homeless mothers with dependent children are particularly vulnerable because they face the difficulties that come with caring for their children on top of dealing with the many issues that arise from having unstable accommodation [17]. Research shows that, compared to homeless women without dependent children, such homeless mothers are more likely to have physical and mental health problems, including alcohol or drug use issues [18,19]. A longer duration of homelessness further exacerbates these problems [20].

The impacts of homelessness on children are also profound and include being far more likely to experience hunger, developmental delay, poor physical health and mental disorders [21,22]. Some of these outcomes may be due to the impact of homelessness on neural development. Bassuk and colleagues, after reviewing recent findings on the effect of stress on developing brains, note that homelessness for children, especially young children, can cause "changes in brain architecture that can interfere with learning, emotional self-regulation, cognitive skills and social relationships" [9]. Children who experience homelessness are also more likely to themselves become homeless as an adult [23]. Research led by Flatau [24] found that intergenerational homelessness amongst those accessing homelessness services was notably high, with half of the 647 homeless respondents reporting that their parents had experienced homelessness.

Despite the prevalence and impact of homelessness, there are substantial gaps in what is known specifically about family homelessness. For example, UK researchers Bradley, McGowan and Michelson recently noted that there is a limited understanding of how homeless parents approach their care-giving responsibilities whilst adjusting to being homeless [25]. They note that further research on the experiences of homeless parents in other international contexts is needed and that such research is essential for informing appropriate and effective support services. In Australia, Nirui and colleagues have urged similar research, noting that literature examining the needs and level of service support that Australian homeless mothers and their children require to break the cyclical nature of homelessness is scarce and mostly based on international studies [5]. Hulse and Kolar have also noted that there is very little Australian research exploring mothers' views on their homelessness experiences and the effects this has had on themselves and their children [26].

Also, under-researched is a sub-group of homeless mothers-younger homeless mothers-despite indications that this group may be particularly vulnerable and require specialised service delivery. Research from the US [27,28] and Australia [4,29] identified that younger homeless mothers face more challenges than older homeless mothers, including various forms of discrimination and stigmatization. This research shows that younger mothers are also more likely to have been abused in their childhood, to have poorer relationships with their parents, to be less knowledgeable about contraception and to be sexually active at a younger age. These findings suggest that younger homeless mothers may face additional challenges and as such, may have different experiences and needs during their journeys into and out of homelessness. However, to date, there is limited research about their specific service needs [28].

Overall, there is currently insufficient research, both in Australia and internationally, that specifically explores the experiences and service needs of homeless mothers and the impact of homelessness on those mothers and their children. Although large and well-funded studies are needed, smaller exploratory studies can also provide important data. For example, a recent exploratory study by Marvin and So used qualitative data from interviews with 10 homeless mothers in emergency 
assistance hotels in the US to identify and elucidate key issues that this group faced-profound isolation, role conflicts, the difficulties of 'living in limbo' and substantial problems meeting basic needs [13].

In this study, a similar approach is used to explore the experiences of Australian homeless mothers. Using semi-structured interviews with 14 Australian homeless mothers and four staff from homelessness service providers, across two Australian states, the current study aims to: (1) document the pathways that led to homelessness for these mothers and their children; (2) identify the services and supports that were valuable and available for these mothers when exiting homelessness, or would have been valuable had they been available; and (3) identify the unique needs of these mothers. Because younger homeless mothers may face more difficulty than other homeless mothers, a fourth aim was to specifically investigate the experiences of younger mothers (between 16 and 25 years) in the sample.

\section{Materials and Methods}

\subsection{Ethics Approval}

Participants gave their signed, informed consent for inclusion before participating in the study. The study was conducted in accordance with the Declaration of Helsinki and the protocol was approved by the Macquarie University Human Research Ethics Committee in Sydney, Australia (Reference number: 5201400573).

\subsection{Design}

In-depth semi-structured interviews were conducted one-on-one with mothers who had a history of homelessness and with homelessness agency support workers. These interviews enabled participants to voice their stories and perspectives on the issues they have faced and identify factors that assisted with the transition out of homelessness. To strengthen the findings, data were collected from two metropolitan welfare agencies in separate Australian states, New South Wales (NSW) and Victoria. Each service was chosen because it was known to the researchers to provide housing and case management support services to a number of homeless mothers and their children, including younger homeless mothers.

\subsection{Participants and Procedure}

Prior to commencing recruitment, the researchers provided training on conducting interviews and assessing whether the interview questions were appropriate. Both welfare agencies then piloted the interview schedules with one mother and one agency support worker and advised the research team that both schedules appeared suitable without alteration (see final schedules in Appendices A and B).

A purposive selection recruitment approach was chosen, primarily around ethical considerations for the welfare of the participating mothers (and in particular the younger mothers we wished to recruit) and to ensure that the agency workers invited to participate had relevant experience. Agency support workers were considered to be in the best position to determine which mothers were best placed to talk about their homelessness experiences and to invite those mothers to participate in the study. The agency managers (who were research partners) suggested which agency staff had duties and experience that best placed them to reflect on service delivery and the issues faced by homeless mothers.

The face-to-face interviews were completed with 14 mothers and four agency staff (see Table 1 for a breakdown of locations). Eligible mothers were at least 16 years old, had sufficient English-speaking skills to be interviewed, headed sole parent families and had at least one child living with them. The welfare agencies selected a sample of mothers at various stages of homelessness, including those who had successfully exited homelessness, as well as several mothers who were younger (aged 16 to 25 years). The agency support workers approached 15 mothers who met eligibility criteria, inviting them to participate. They were informed that they could decline to participate in the study or 
withdraw from it at any time without consequence but that they would receive a $\$ 30$ food voucher if they did participate. One invited participant declined due to time constraints but the other 14 mothers agreed to be interviewed. The characteristics of the final sample are shown in Table 1.

Table 1. Socio-demographic characteristics of participating mothers and support workers.

\begin{tabular}{lc}
\hline Mothers & $N=\mathbf{1 4}$ \\
\hline Mean age (range) & $27.86(17-46)$ \\
Mean age at which participant gave birth to first child (range) & $21.29(16-31)$ \\
Total younger mothers aged 16 to 25 (teenage mothers) [mothers 16-21] & $8(1)[5]$ \\
Mean number of children (range) & $1.79(1-4)$ \\
Age range of children & 3 months to 25 years \\
Number from culturally diverse background (\%) & $5(36 \%)$ \\
Number with intermittent partner (\%) & $2(14 \%)$ \\
Number who experienced homelessness prior to becoming a mother (\%) & $9(64 \%)$ \\
\hline Number of homelessness episodes experienced since becoming a mother & \\
One to two & $3(21 \%)$ \\
Three to six & $3(21 \%)$ \\
Seven or more & $8(57 \%)$ \\
\hline Type of accommodation reported at time of interview & \\
Currently in crisis & $1(7 \%)$ \\
Transitional accommodation & $4(29 \%)$ \\
Long-term agency housing & $3(21 \%)$ \\
Long-term government housing & $3(21 \%)$ \\
Private rental & $3(21 \%)$ \\
\hline State & \\
New South Wales & $6(43 \%)$ \\
Victoria & $8(57 \%)$ \\
\hline Agency Staff & $N=4$ \\
Number who are female (\%) & $4(100 \%)$ \\
Mean duration of employment at welfare agency (range) & $5.0(0.7-12.0)$ \\
\hline State & \\
New South Wales & $2(50 \%)$ \\
Victoria & $2(50 \%)$ \\
\hline
\end{tabular}

Briefly, mothers were on average 27.86 years old at the time of interview (range 17-41) with eight of the 14 mothers being younger (under 25), five of the mothers being 21 or younger and one being a teenager. Mothers were on average 21.29 years old when they gave birth to their first child (range 16-31), with $50 \%$ of mothers reporting their first pregnancy during their teenage years. The majority experienced homelessness prior to falling pregnant (64\%) and, importantly, over half had experienced at least seven different episodes of homelessness since giving birth to their first child (57\%). A brief description of each mother's circumstances can be found in Appendix C.

Written, informed consent was obtained by the agency support worker prior to the interviews taking place. At the time of the interview, an agency support worker introduced the interviewer to the participant and offered to remain present during the interview. The interviewer showed the mother the Participant Information and Consent Form to ensure she did not have any further questions, reminded her that the interviews were anonymous and confidential and reassessed consent. To ensure anonymity each mother was identified only by the letter ' $\mathrm{M}$ ' (for mother) and a number. Interviews with mothers were conducted either within their homes $(n=5)$, at the agency $(n=5)$, or at a café $(n=4)$. The agency support worker was only present for the interviews held within the mothers' homes and assisted with child-minding when needed.

The interview schedule for mothers covered questions on demographics, housing situation, homelessness history, welfare service engagement, perceived barriers to housing and issues pertaining to specifically to younger mothers (see Appendix A). Interviews ranged from 24 to 59 min and mothers received a $\$ 30$ food voucher on completion. 
Eligibility criteria for agency support workers were that they had sufficient English-speaking skills to be interviewed and had at least six months experience working with homeless mothers. All four agency support workers approached for an interview provided written, informed consent. Interviewed workers were all female, had been working with their respective agencies for between 7 months and 12 years and were experienced in providing case support to homeless mothers, including young mothers. The agency support staff interviews answered questions about their role within the agency, perceived strengths and weaknesses of service provision, perceived needs of homeless mothers and their children and specific considerations for younger mothers (see Appendix B). Interview duration ranged between 49 and $72 \mathrm{~min}$.

All participants provided consent for their interviews to be digitally recorded. Interviews were transcribed verbatim and de-identified.

\subsection{Data Analysis}

Transcripts were read several times and comparisons were made within and between transcripts. This process facilitated the development of a list of codes and set of coding rules, which were determined both deductively (i.e., derived a-priori from existing literature and the research questions) and inductively (i.e., derived from the content of the interviews). Thus, the coding scheme reflected themes determined by the interview schedule and research questions, as well as other themes that emerged from the interview data. All interview transcripts were then entered into NVivo 10 software (QSR International, Doncaster, Australia) and coded line-by-line according to the meanings, perspectives and actions which were represented and according to contextual factors in their generation. This thematic coding was reviewed by two researchers for consistency. Quotes selected for inclusion reflect the experiences and views of participants and were chosen based on their relevance to the research questions and emergent themes. For these quotes, mothers' interviews are signified by identification codes beginning with ' $\mathrm{M}$ ' and those from agency support staff begin with 'A.'

\section{Results}

Participants' perceptions of homelessness for mothers and their children clustered into three key themes that aligned with the key research questions and the interview schedule-pathways into homelessness, specialist assistance and service delivery aspects that mothers require to successfully meet their needs and exit homelessness and unique issues faced by younger mothers. Within each of these three overarching themes, various sub-themes were identified in the data.

\subsection{Entry of Mothers and Their Children into Homelessness}

\subsubsection{Factors Contributing to Homelessness Entry}

Participants identified a number of relational factors that contributed to becoming homeless. Domestic violence was the most common reason for homelessness entry after giving birth to a first child, with seven of the mothers reporting fleeing domestic violence and another implying it. Often little thought was given to how they would house themselves or their children: "All I was thinking was our safety. I don't think about the bills and things like that, it was irrelevant" [M13]. Mothers also noted other relational issues that increased the imperative to leave secure housing. Some mothers noted that they did not want to stay in a relationship, or raise a child, with a partner who used illicit substances: "He was still involved in drugs and stuff and I didn't want to be around him after I had the baby ... I wasn't prepared to put my daughter at risk" [M7]. "We moved away from there because of his drug addiction" [M11]. Finally, some of the mothers reported leaving secure accommodation because strained or broken family relationships had made staying with family very difficult: "Yeah, family problems ... we just didn't want to stay around and wanted to have a better life for our little one. So we decided to leave and have a fresh start" [M3]. Sometimes family issues and related threats of violence interacted to provide an impetus for mothers to leave secure accommodation: 
"... my mum is being really aggressive and really on with me. And she has someone after her because of a big debt. And also because she said something about him. He is a really, really nasty fellow. And I don't want to be around when that happens because I know the guy is getting out soon. ... So I left" [M7].

In terms of socio-economic factors, mothers commonly reported that poverty, financial difficulties and/or unstable housing as children/adolescents or young adults preceded or contributed to their becoming homeless with child. Most mothers noted that their low incomes made finding stable housing very difficult: "I thought about going private but I am not making any income so I won't get that ... I won't be able to get a house and all that sort of thing-I am just surviving where I am" [M4]. Seven mothers reported childhood/adolescent and/or pre-pregnancy homelessness and for six of these mothers housing instability prior to having their first child was followed by further homelessness after having their first child, a pattern of intergenerational homelessness.

Importantly, the length of time taken to first access homelessness support services seemed to be an important determinant in whether homelessness became more entrenched for these families. In this sample, eight of the 14 mothers had experienced homelessness seven times or more since their first child, with these mothers typically having delayed engagement with services. In contrast, three of the remaining mothers who accessed accommodation support services soon after first becoming homeless reported just one or two episodes of homelessness. For these mothers, early engagement seemed to be protective against re-entering homelessness multiple times.

\subsubsection{Uncertainty}

Mothers in transitional housing at the time of interview emphasised the constant uncertainty they were living with while waiting for long-term housing: "Just the stress-factor and the insecurities that my daughter has to face not knowing exactly what is going to happen. And I can't give her an answer on when they are going to have something for us" [M7]. For these mothers, transitional housing was reported as providing them with only temporary stability, as they were aware that it was inevitable they would have to move their family and belongings in the near future and did not feel that the accommodation was truly their home: "... even though we are in a transitional property, that is what it is: transitional. We are still going to have to move again" [M7]. "If I had a home I could set up a future. But right now it feels like whenever I take a step...it is like, 'Where is your home?' or 'What would you do if a new home comes?' You know? You might be in an area and set up with the doctors now but if I get a house then I have to change" [M14].

\subsubsection{Challenges to Successfully Exiting Homelessness}

Various challenges to exiting homelessness were described by the mothers. A number reported that (a) long housing waitlists and (b) not knowing exactly how long the wait to receive housing would be, were issues that made exiting homelessness difficult. "I went to Housing Commission and said I need to find a house and whatever and they were like 'it is an eleven year wait' ... and I was like, well, how the heck am I going to survive?" [M4]. "You are being told that you have got to wait. ... why not let me know how long it will take? At least then you have a more precise timeframe" [M14].

The unaffordability of private rental and a lack of information and knowledge about the services that were available, were difficulties echoed by almost all mothers: "We can't afford to be in private rental" [M2]. "I just couldn't get an affordable place for me and the girls" [M8]. "I didn't even want to think about how I was going to pay the rent, or how I was going to afford to live in a private house" [M9]. "I didn't know about all the services because I was 11 when I first started living out of home" [M5]. "I didn't know about the community housing or anything. I would just go to the random place that I lived and cry in the night and sleep and go throughout the day to look at places that I couldn't afford" [M9].

Some mothers reported issues related to having to accept lower housing standards in order to have somewhere to live (i.e., being asked to live in an area with high rates of crime): "... they put you in bad areas. I don't want to live around druggies" [M8]. 
Agency staff identified a number of service delivery challenges they face in their efforts to assist homeless mothers to exit homelessness:

- Making sure clients are ready for what the housing programs entail before entering them: "You rush them in. You are getting in ASAP. Our success rate with that hasn't always been very high, because they are not really ready for it. They are just looking for housing, that roof over their head. But then to teach them how to maintain their home, pay their rent, pay the charges they have to pay within the service" [A2].

- $\quad$ Accessing appropriate services in a timely manner (e.g., psychologists): “... cognitive therapy stuff needs to be done but to get hold of that in a service like ours or other services is really challenging. The waiting lists are long, the accessibility is difficult for some young people, that kind of thing" [A2].

- Helping clients to readjust their goals to achieve the best outcomes for their families: "Because we do have a lot of young girls over the years who have brought in multiple partners and it is like, how is that affecting your children? ... it is about those conversations, ... 'well, what do you think is best? What do you want to achieve for your family?'" [A2].

- $\quad$ Agency workers managing their own personalities and attitudes when working with young mothers to ensure a positive working relationship: "Our weaknesses are our personalities, or anything like that, that can clash with the young people" [A2].

- $\quad$ Helping clients to realise the costs associated with living in stable housing: "... when you bring them into a program where ... this portion of money has got to go to your housing, your food, your electricity, to maintenance and all that sort of thing ... they are like, 'You are taking all my money.' And it is just like, 'No, these are normal living costs'" [A2].

- $\quad$ The challenges involved in placing homeless families in private rental properties. For example, when a client family agrees to private rental housing, agency staff become responsible for chasing that family for any rental arrears they may be co-contributing toward their rental payments: "... then this expectation that they have to look for private rental-putting that pressure on them. And you can negotiate with that but I think it is an additional stress that some families can't cope with. ... So if they are doing co-contribution, it is my job to manage that they are paying rent. You get a lot of complaints from the accommodation provider saying that so-and-so hasn't paid" [A3].

Agency staff also reported several industry- or organisation-level issues when trying to house homeless mothers and their families:

- $\quad$ A perceived lack of coordinated support within the sector: "I think it seems like there is a lack of support, coordinated support in the sector. There might be different programs working in silos as well, which makes it a bit tricky" [A4].

- $\quad$ Insufficient on-going government funding. One agency reported it would likely need to find philanthropic funding to offset government funding cuts in order to continue their service: "It is a bit precarious at the moment. I think we will really need to look at philanthropic funding than being reliant on the government, especially with a new [conservative] government who are cutting services. ... So that makes things a lot more difficult. We have just recently had one of our programs here lose over $50 \%$ of its funding" [A4].

- When young mothers enter the programs offered by the welfare agencies, they are moved from the high priority government housing list to low priority because they had transitional housing through the program. Once the two-year program is finished, however, they continue to be deemed as low priority by the government housing authorities, even though there is no long-term housing offered for young mothers exiting these programs. Consequently, as the mothers and their children exit the program, they are at high risk of re-entering the cycle of homelessness. This may partly explain why more than half the mothers interviewed had experienced seven or more periods of homelessness. 
"What would happen is around about 18 months in we would then start to look at what they would be moving to, what they would be entitled to. ... Because we are a homelessness service, the young people that come in to us ... are passed as high priority homeless, because we are a homelessness service, so they don't have full housing, they've just got transitional. If we send them to [Department of Health], or Housing NSW, they say 'No, you've got a place, you are not top priority.' So it actually creates tension because they say, you've got housing, you don't need to be on the [priority housing] list. ... [the clients] finish with us and then go back to live with mum or dad or someone who they then have a blow-up with and then end up back out again. And then they come back into that cycle again" [A2].

"How do you break the cycle of homelessness when you have no exit housing, when you have nowhere to take these young people on to ... there is no exit housing for homelessness services" [A2].

- $\quad$ There are often very limited long-term housing options that are appropriate for young mothers exiting these programs: "In terms of housing it is not just about affordability but having safe housing is a big issue. For housing to be sustainable, it does have to be affordable but it needs to be within their community, it needs to be safe and have good amenities and facilities nearby. So that is another service constraint" [A4].

- Instances were noted whereby agency staff had found it difficult to both adhere to organisational processes and also provide personalised client support. These issues were further exacerbated when agencies had changes in management and consequent changes in procedures and processes to which both agency staff and clients needed to adapt: "... anytime a manager came on board there was always a difference around how that person managed things. That brings about change within the program" [A2].

3.2. Specialist Assistance that Mothers and Their Children Require to Meet Their Needs and Successfully Exit Homelessness

\subsubsection{Personalised, One-On-One Support}

Most agency staff felt that the personalised, one-on-one support given by their respective agencies was a core strength. Agency staff stressed the importance of the duration (up to two years) and diversity of support, which encompasses both housing and everyday needs. "I think it [the greatest strength of the program] is the stability in housing, the one-on-one support, the care that is given around that housing and the attention that is paid to their personal daily needs - their food, their clothing, their shelter, their connecting with other people of a similar age" [A1]. The majority of mothers also identified the constancy of support and genuine care shown by the relevant agencies as valuable attributes. One mother [M4] reported that going to the agency's centre and their functions felt 'like you are at home', with the support workers being like 'another family.' "I think just the way that they were so friendly and so willing to help you and they didn't know you from a bar of soap" [M4].

A number of mothers reported that support from the welfare agencies was their strongest (and often only) form of support during episodes of crisis: "... they help you calm down, they show you what to do. There are people you can talk to so you can know who you are again" [M12].

\subsubsection{In-House Support Programs}

The in-house programs offered by the welfare agencies were deemed valuable by both the mothers and agency staff. Specifically, the parenting and mothers' groups were often identified as the most helpful aspect of the services, especially among the younger mothers who felt that these programs increased their confidence to parent: "I really found the parenting one very useful ... I learnt heaps more stuff from them" [M3]. Agency staff also identified that programs which focused specifically on the case management of children were valuable, particularly in terms of their social and emotional development. Life skills programs that covered a range of areas (e.g., finances, household duties) were deemed as helpful for a range of clients, as well as activities that encouraged socialisation among young mothers: "... socialisation is really important for young mums with kids so that they are meeting with other young 
mums" [A1]. However, some mothers felt that the courses they undertook were sometimes provided at a time when they were unable to derive the full benefit. Agency staff reported that education and employment were often low priorities for mothers when they first engage with the services, so these were addressed as long-term goals when appropriate.

\subsubsection{Partnerships with External Services}

Agency staff reported that partnerships were established with external services for the purposes of referring clients to them if they could not address a particular need. Examples of external referrals included health services (including child speech therapist and domestic violence counselling services), jobs skills training, youth specific services and hands-on mother and children playgroups. One agency staff member also reported a strong working relationship with child protection services in order to provide the best support to families, whilst being transparent about the care and support provided to families with the relevant agencies. Some agency staff also identified existing relationships with other housing agencies for the purposes of referring to them if their own agency had reached capacity.

To strengthen partnerships with external agencies, it was suggested by agency staff that a more coordinated approach between agencies was needed, which could be facilitated through more formal memorandums of understanding between agencies. In particular, coordinated case management was deemed as a positive approach, as it can enable specialised services to come together to provide holistic care to mothers and their children: "It is just what is needed: a coordinated approach" [A4].

Mothers indicated that better service integration would be beneficial during times of crisis, as they had previously needed to shuttle between services for different forms of assistance: "Instead of looking for work and getting yourself ahead, you are actually surviving. Because you have to run around to all these different places instead of having one person to say, 'Okay, this is what is needed'" [M14]. It appeared that this issue often caused confusion and angst for mothers, who were already under significant stress through being homeless. One mother [M14] also pointed out that while mothers may become homeless during the night, services are often only open during business hours (e.g., 9 a.m.-5 p.m.). These restricted operating hours would likely be particularly problematic for mothers in a crisis (such as fleeing domestic violence) who are unclear as to where to go or what services are available out of hours.

\subsubsection{Individualised Supports for Each Family Member}

Whilst it is important for support to be provided to the family unit as a whole during episodes of homelessness, it became clear during the interviews that providing specific support to each individual within the family unit is very important. In terms of support for mothers, social, educational and employment assistance were most commonly noted as important.

Mothers described a wide range of levels of social support external to the agencies. Whilst some mothers reported little or no support, a young Aboriginal mother reported substantial social support and connectedness [M3]. Similarly, some mothers expressed that they did not want social supports outside of the welfare agencies, whereas others reported a strong desire for social connection. However, some mothers specifically mentioned that they would benefit from a homeless mothers' playgroup or something similar that would allow them to compare experiences in an environment where they would be unlikely to be judged or stigmatised:

M11: "But they don't have a group where you could go and sit, like a playgroup. They don't have somewhere where you can go with your kids and your kids can play and all the girls can talk. They don't have anything."

Facilitator: "Is that something you would be interested in?"

M11: "That would be perfect. Playgroup is good for the kids and Mum's group, talking to other mums-but mums who are in the same situation. I don't want to go to playgroup and they say 'so where have you come from?' Because some mums might be like 'we don't want our kid going to her house, what if...she has nowhere to live and she is single.'" 
Younger mothers, in particular, expressed having issues with staying socially connected. Some reported struggling with the competing desires of wanting to socialise with their peers as they had done before having a child and the responsibility of looking after their children. "I' $d$ find that your social life is a big thing that you don't get ... as a single mum and all that kind of thing ... your main best friend was the smart one which didn't fall pregnant and can go out and go partying and stuff ..." [M4].

In terms of educational and employment program supports for the mothers, a number reported that they were currently completing educational courses to enhance their skills. These mothers mentioned that the agency staff had worked with them to identify their goals and potential avenues of study and subsequently assisted them with the application and enrolment process. Other mothers who had qualifications that would allow them to work and look after their children spoke about their goals of finding employment in the future but this was not identified as an immediate priority, especially for those in transitional housing.

Encouraging mothers to send their children to childcare was deemed by all support workers and some mothers as having benefits for both mothers and their children. The welfare agencies had played an active role enrolling some of the children into local childcare facilities. Agency staff emphasised that the socialisation of children is critical for their social and emotional development, especially since most are not used to regular social interaction due to the transient nature of their housing situations:

"Child-specific [approaches are] more around trying to get them into childcare and making sure that their social and educational development is there ... a lot of the children are brought up with adults only, they are not used to having that social interaction. ... really recognising that a child needs social and emotional development as well." [A2].

Further, it was noted that encouraging the mother to have some 'me time' when the child[ren] were in care, where she can focus on herself as a woman, not as a mother, can be beneficial and would allow her to focus on some of her own goals, such as commencing study:

"Sometimes it is about tailoring the conversation about 'well, how do you feel about putting your child into childcare maybe one or two mornings a week so that you get a bit of a break so that you can just relax, take a breather and do better at mothering'" [A1].

Although some mothers reported that childcare had been helpful: "the childcare was great" [M3], others reported feeling uncomfortable leaving their children in care because of separation anxiety or trust issues for themselves "I had a bit of separation anxiety there" [M5] or their children: "I had this child who had major anxiety over me leaving [her at childcare] ... she just wasn't doing well there" [M7].

Other supports that were reported as being helpful included receiving assistance for schooling and youth services (e.g., money for uniforms and books) [M8], child counselling [M10] and being moved from shared housing (where children tended to be disruptive and unsettled) to accommodation where the family had private space:

M4: "one of the mums [in shared housing] was a yelling mum and yelling at the kid all the time and that upset him and he wouldn't go to sleep. So then I knew that it was time to go. And he was getting older too, he wanted his own room and that kind of stuff ... It was unsettling him and I thought 'nope, I have had enough' and it was a lot of work-especially for a single mum."

Facilitator: "So did you raise the conversation with X that you wanted your own property?"

M4: "No, they actually raised it with me. ... and then they said we want you out as soon as possible and it took like two weeks and I was in there straight away, which is a bonus. It is far away but it gives me time to socialise with my friends and family and have my own time in my own house with my son. He has his own room and stuff." 


\subsubsection{Suggested Improvements to Service Provision}

One mother reflected that if rental agencies were informed that the welfare agency would support a client who receives housing to maintain the tenancy, then this would have assisted them to have remained in stable housing: "Just to have someone behind you so that when you do go to hand in your rental form, they can see that there is someone to support you" [M10]. Another mother reported that it would be helpful for support services to send a letter to rental agencies to certify that the mother is being supported to maintain the tenancy [M13].

Agency staff felt that a commitment to increased and flexible funding and a larger pool of suitable accommodation options, were needed to improve to service delivery: "More money. More access to stock housing. More access to community housing. ... Just more housing options really" [A3]. Increased funding would allow homeless mothers to be allocated an agency staff member more quickly and enable more specialist agency staff to be recruited and upskilled. Some agency staff felt that the terms of their funding were sometimes restrictive and should have inbuilt flexibility. For example, typically the welfare agencies can assist mothers for up to two years, however there were cases where mothers were forced to exit after this period despite being unready. Such mothers could re-enter only when they had demonstrated experiencing further difficulty:

"The two year contract. At the end of the contracted time, some people—let's face it-aren't ready. ... So after the two years, they might try and live somewhere else but it is not working, or something has fallen through and they will make contact again. And they might not come back on a program exactly the same ... even if they fall through what we are offering, we still try and give them something" [A1].

In terms of accommodation options, a number of agency staff emphasised the continual need for 'more affordable housing' options [A4] and 'better housing in better areas' [A2]. Mothers also echoed this point of needing long-term housing options in safe suburbs [M7, M9, M10] and crisis and short-term housing options that are appropriate for mothers and children. One mother noted that when she was eight months pregnant "I went to housing, they kept just giving me options of living in a rooming house and I was like no way would I live in a place like this, you can't even sleep on the bed because of bugs. ...your safety is not guaranteed, you don't know who is coming in and out of the house ... it just didn't feel right, so I would rather just stay in my car" [M14].

\subsubsection{Benefits of Being in Long-Term Housing}

Mothers who were in long-term housing at the time of interview were asked how life had changed since moving into permanent housing. Most mothers reported feeling safer, that they now had much more stability and routine in their lives and that their children's and their own happiness levels had increased: "But now I actually know that it is a home for your family, no one can just come in and out of your house. I love my own home, you can just do anything, the kids can do anything ... It's my home ... yeah, happy" [M3].

A reduction in stress since moving into permanent housing was also reported: "Even the pressure and knowing that we can go home, you know? We are not fossicking around out all day waiting for my friend to get home so that we can go there. We can play. My son can ride his bike at home. They have their own toy section ... you can make as much noise as you like. ... Not thinking, when I am moving from one place to another, I have got to clean up. I am trying to look after them but the pressure of having to keep someone else's place tidy" [M11].

Finally, one mother reflected that her family now felt much more content and were able to make long-term plans: "Just a lot more content. Yeah, like the feeling of not having to pack up soon. Or, like, thinking long term, if I wanted something I wouldn't have to get rid of it eventually, wouldn't have to get up and go. I think that is the main thing. Yeah, just content really" [M1]. 


\subsubsection{Supports to Maintain Long-Term Housing}

A number of mothers expressed anxiety about maintaining private rental properties. Issues such as affordability, uncertainty of lease duration and having to keep up to date with payments were raised:

"Well, the rental would be hard. Just me having a panic attack and forgetting every appointment for a week. Because if I have a panic disorder, I forget everything and can't keep appointments or remember what I have to do. And I find it hard to even look in my diary and function. So these things I just need to keep on top of" [M7].

Mothers also emphasised that they would like the supportive element of the services to continue once they are in long-term housing. Mothers viewed this support as a safety net, as they felt the agency staff would remind them of the essential tasks they needed to complete to continue with a normal routine.

\subsection{Service Delivery Considerations for Younger Mothers}

\subsubsection{Supports Required for Younger Mothers}

For younger mothers, both agency staff and the mothers themselves commonly identified that a constant level of support is critical: "[The Welfare agency was] supportive with everything, even when I was upset or crying, or not in a good mood, they were really supportive. Sometimes all you want is someone to listen to you. And just to help out with the small things. Yes, housing is the main thing when you are homeless but sometimes it is the small things: making a phone call for that person, or getting them that form" [M10].

Agency staff also identified the need to offer younger mothers more support in relation to facilitating a more normal developmental trajectory for their child: "I have found with a lot of young mums that they expect their children to grow up fast ... teaching them what is normal development and what they can and can't do and what their expectations should be of their children is really important for younger mums" [A2].

As noted in Section 3.2.4, some younger mothers reported that they would value spending time with other young mothers in a similar situation, as such a group would provide and receive support from each other. Both mothers and agency staff stated that it would be beneficial for young mothers to talk about specific topics with each other, such as housing or financial services, so that they could hear other people's situations, get ideas or advice, and not feel so isolated. One agency staff member noted the importance of providing accurate information to younger mothers: "We had the rental people come in and we had the Department of Housing guys come in so that they could ask specific questions around what some of the barriers they were facing in private rent and that kind of stuff. ... Because [while] a lot of young people learn from each other, they actually don't have anyone who actually has a professional understanding or knowledge ... the truth about what really happens, so 'that's just what my friends told me, my friends told me you can't do this etcetera'" [A2].

A minority of younger mothers reported that they felt stigmatisation and a lack of social acceptance for their situation: "People judge me because I have a baby at a young age ... you're young, you were silly, you did that mistake but you've done the right thing and not got rid of the child and you still get judged for that ... And it's not just they want to make you feel bad about it, it's you have to deal with it yourself" [M4].

Younger mothers also reported feeling stress, the financial pressure of being a single parent with minimal family support and self-blame for being a young homeless mother. They also described various practical difficulties that came from being a single homeless mother, such as trying to visit a service with both their children and belongings in tow.

Agency staff raised the additional issue of younger mothers having less knowledge about the services that are available to them than older homeless mothers. Further, because younger homeless mothers often did not plan to become pregnant and had not thought about the practicalities of being a 
parent, agency staff noted the need to engage with and teach younger mothers around the basic skills needed to manage a household, budget finances and raise a child:

Facilitator: "So more basic things for the young mums?"

[A1]: "Very basic needs. ... they didn't usually plan to get pregnant and they weren't thinking about what would come after. So it is usually an education around that sort of thing and encouragement and provision of brokerage to help them get what they need and just talking through budgeting issues is one of the main ones. Because a lot of young mums see buying lots of stuff as being good mothering, so 'I will spend $\$ 1000$ on their birthday on Saturday and I have bought this and I have bought that and I have bought something else' because that's perhaps what they have missed out on. Perhaps that is what they see as good mothering but just showing them that the everyday stuff is really important. It is okay to spend $\$ 1000$ on the birthday party but if your fridge is empty on Monday and there is no food, then what are you going to do?"

Finally, other priorities for younger mothers, such as their social activities, have to occasionally be assessed by agency staff, as these mothers are still in their youth and struggle with self-discipline and forward planning. Agency staff viewed this type of assistance as critical to younger homeless mothers, because ultimately, if they cannot get their priorities in order, these mothers may lose their children. It was noted that this can be particularly challenging when working with younger mothers who are using substances, as such mothers may not be aware of their children's needs and frequently have difficulties knowing their own needs: "It is very much a part of our program to focus on the needs of the younger mothers - their own personal needs but also the children's needs. But sometimes-especially where drugs are involved - they are not looking at what their children's needs are and they are not really able to see their own either and that is so sad but unfortunately there isn't much we can do" [A1].

\subsubsection{Improving Service Delivery to Younger Mothers}

In terms of improving service delivery, younger mothers reported that they wanted homelessness service providers to provide greater clarity around the other services and programs that they could access and to be more transparent during the process of obtaining housing:

[M14]: "I don't know how they prioritise and I don't know how the system works and whether they actually do have homes available or they don't. ... if they could offer a bit more guarantee of your situation, tell you the actual truth ... you see people crying there at the office and it is more that they are not telling you the truth ... 'I can't give you this, you have to go to this service.' ... if they could just have one office where they say 'go there ... you are homeless, okay, for two nights we can put you at a hotel and there is this house coming up, would you like it?' I don't know."

Facilitator: "Yeah, sure, so a bit of a one-stop-shop."

[M14]: "Yeah, rather than going here, there and everywhere."

[M14 later]: "If there was more of a one way street to finding affordable housing where you can be told what your options are."

Facilitator: "So a bit more transparent?"

[M14]: "Yep, 'this is available, do you want it or do you not want it?'"

The importance of advocacy, support and obtaining safe housing quickly was also reported by younger mothers: "Having someone who is determined to [get you a secure place, to help you out, to get all your needs in order] and someone who will stand up for you so that you don't feel left out, let down...that would be good" [M6]. 


\section{Discussion and Conclusions}

The aim of this paper was to build on the scant knowledge base about the pathways to homelessness for Australian mothers and their children and the services this group need to access in order to break the cycle of homelessness. A further focus was on the needs of a particularly vulnerable sub-group-younger homeless mothers. This was an exploratory study with a small purposive sample and no control group, so it is not possible to draw causal inferences from the data nor to generalise the findings to a wider population of homeless mothers. Nevertheless, the findings provide a valuable insight into the experiences of the homeless mothers and agency workers in Australia.

Three findings were particularly salient. First, in terms of factors that contributed to homelessness for these women and their families, the most common was domestic violence. In addition, a number of homeless mothers had themselves experienced early or pre-pregnancy housing instability and homelessness, thus demonstrating a pattern of intergenerational homelessness extending from mother to child. Second, almost immediate engagement with the welfare agencies that provide housing stability and support, may have been protective for these mothers and their children against re-experiencing homelessness. Third, the restrictive and limited housing options available to homeless Australian mothers and their children when they exit homelessness programs places them at high risk of falling back into the cycle of homelessness.

The finding that a number of the homeless Australian mothers interviewed had experienced either (or both) domestic violence and early homelessness is consistent with existing literature [6,7,23,24]. In Australia, domestic and family violence was the primary reason that accounted for almost half of the women with children who sought assistance from SAAP services in 2012-2014 [6], with an increase of 7000 shown between 2012-2013 and 2013-2014. Much of this increase (about three quarters) was in Victoria, the state in which eight of the women interviewed in this study sought assistance. The number of homeless families fleeing domestic violence has continued to remain high. Specialist homelessness service clients fleeing family violence made up 38\% of the total clientele in 2015-2016 and 40\% in 2016-2017, with almost half being single mothers with children [7]. Clearly, many mothers and their children are still forced into homelessness to flee family violence, despite a concerted effort in Australia to combat both homelessness [2] and domestic violence [30].

Similarly, several of the families in this study demonstrated intergenerational homelessness despite this issue having been identified as problematic in Australia for some years now [23,24]. To break this cycle, it seems crucial that (a) homelessness is identified early and preferably before homeless children and youth themselves become parents to children who may also become homeless and (b) that those who exit homelessness programs remain in stable housing. The data in this study reinforce the importance of early engagement and a successful exit for homeless mothers.

Mothers who reported experiencing only one or two episodes of homelessness had all quickly engaged with welfare agencies when they were first homeless. This contrasts starkly with those mothers who had experienced more than seven episodes of homelessness (the majority in this sample) but had typically not engaged with welfare agencies during their first few homelessness episodes. This suggests that when mothers and their children are supported by programs that offer individualised one-on-one support, such as those examined here, there may be a reduced likelihood of them re-entering the cycle of homelessness. Early engagement with such services may bring other benefits as well - earlier placement into long-term housing and a concomitant sense of stability and continuity related to having a 'place to call home.' What is not clear from the data is whether the same pattern of benefits would hold for all early-engaging homeless mothers. Those mothers who engaged with services more quickly in this sample may also have been more skilled and more motivated when it came to locating and gaining benefit from those services. Future studies may benefit from examining whether there are unique characteristics among early-engaging mothers that contribute to their success in homelessness programs. However, even if it is found that early engagement with services may benefit some mothers more than others, it is hard to envisage a scenario where early service engagement has no benefit at all to homeless mothers and their children. 
In terms of a successful exit to homelessness programs, these data suggest that in the Australian context, where there are often funding agreement restrictions to how long homelessness services can be provided (typically two years), there are two key points of possible failure-mothers being themselves unready to leave the program and a lack of suitable housing available to exiting mothers. It was clear from interviews with agency staff that the two year mandatory exit point (and the funding inflexibility which underlies it) does not serve well those mothers who, two years into a program, are still struggling to attain the basic skills needed to budget, run a household, care for their family and manage their own problems. The group most at risk of this may be younger mothers, as in this study younger mothers were reported to have less knowledge and skills on entering programs and to require greater input from agency staff to attain them. In any case, mothers of any age not sufficiently ready to exit homelessness programs may be at higher risk of re-entering homelessness.

As mothers approach the mandatory exit time point and begin to look for accommodation alternatives, they are also faced with the challenge of being categorised as a low housing priority by state government authorities in Australia because they are currently living in transitional accommodation. As such, their accommodation options are limited, particularly since there is a serious shortage of long-term supported housing options for mothers and their children in Australia that they can relocate to upon exiting the programs.

When examining the impact of a mandated two year exit, it is also important to note the context in this study-homeless mothers and their children are a particularly vulnerable group and research has already demonstrated that continued homelessness can have substantial negative consequences both to the mother's mental and physical health and the child's healthy development $[9,18-22]$. Younger mothers may be more vulnerable again [4]. With this in mind, it seems very important that Australian funding, policy and program initiatives (a) provide adequate client preparation so that homeless mothers can succeed upon exiting the programs, (b) allow for longer program times or greater post-program assistance for some mothers and their children and (c) provide permanent priority post-program housing to homeless mothers and their children to break the cycle of re-entry into homelessness.

A further finding of interest was around the meeting of key needs. Mothers consistently reported the need to feel safe, for housing to be stable and to be socially accepted for who they were. Participants also consistently stressed the need for stronger supportive networks, especially with peers. Agency staff reported that the homeless mothers often struggled to effectively utilise educational and training opportunities when their basic needs weren't met. These findings clearly align with the processes described in Maslow's hierarchy of needs model [31], which assumes that individuals must first direct their efforts to meeting their most basic needs (food, shelter, safety), before then attending to intermediate needs such as social belonging and self-esteem. It is only when both basic and intermediate needs are sufficiently met that individuals are then able to pursue higher goals and fulfilment and so reach their personal potential. Throughout the interviews, both mothers and their agency support workers made it very clear that obtaining stable housing and a safe environment were their first priorities and they did not have the capacity to assess educational or employment opportunities until these basic needs had been met. In Australian society, which aspires to being a 'civil' society, the ultimate goal of social services is and should be, for all Australians to have the opportunity to reach their potential-a situation that benefits both the individual and wider society. Therefore, homelessness services should directly, or through referral, be able to assist mothers first with basic needs and then, when appropriate, support intermediate needs and aspirational goals.

Overall, it appears that there is a need for services to meet the basic needs of mothers and their children and then work towards providing her with the support needed to develop positive skills and patterns for the long-term that will enable her to be self-sufficient. However, this needs to be achieved in a way that does not make her dependent on the support services day to day. With younger mothers, more intensive, personalised approaches seem indicated. Where progress towards being ready to enter long-term housing is slow, there should be flexibility around program duration to 
maximise the likelihood that homeless mothers, when they do exit the program, are more likely to succeed in maintaining stable housing. In addition, affordable, safe, long-term housing needs to be available. Strategies which incorporate these factors may have some success in breaking the cycle of homelessness for Australian mothers and their children.

As already noted, this was a small scale, exploratory study with the limitations inherent using such a methodology. In addition, only mothers who had already engaged with the welfare agencies were interviewed. Future, larger studies could build on these findings in a number of ways that might be beneficial to policy makers and service providers tackling homelessness in Australia. First, research that follows homeless mothers and their children for three to four years to determine their specific, long-term needs seems a crucial next step. Importantly, such a study could shed light on the factors that cause those who leave homelessness programs to become homeless again. It may also be valuable for future studies to interview mothers who had recently entered homelessness but had not engaged with the homelessness welfare agencies, in order to understand their perceptions of the sector and gauge how difficult it is for such mothers to navigate the system and obtain correct information. Finally, there may be benefit to future research which examines the efficacy of long-term supported housing options for mothers and their children, to determine which supported housing models work best. A comparison of post-housing support levels across the different housing models may also shed light on how to best assist homeless mothers and their children.

Homeless mothers and their children are a unique group. They are vulnerable, but, if ably assisted, have the potential to break free from many of the restrictions and hardships that homelessness seems to impose. Although the challenges this group face are complex and multifaceted, the benefits of tailored support are considerable for these families as well as for society. Even more important, such benefits can be passed onto the children of homeless mothers and may span across generations, helping to break the cycle of intergenerational homelessness.

Acknowledgments: The current study was funded by a $\$ 25,000$ AUD grant by the Mercy Foundation (in Australia) under their 'Grants to end homelessness' program, which funds research and projects that 'contribute to the goal of ending homelessness.' The funded project title was "Working towards ending homelessness: Building the evidence base on the pathways into and out of homelessness for Australian mothers." The authors also wish to acknowledge the agency staff from Fusion Western Sydney and HomeGround Services who provided assistance with this research. Finally, the authors acknowledge the mothers and agency staff who participated in the interviews and thank them for their generosity and openness.

Author Contributions: Wayne Warburton, Marina Papic and Elizabeth Whittaker conceived and designed the study, co-wrote the grant application for study funding and were co-grant holders. Marina Papic and Wayne Warburton wrote the ethics application and obtained ethical approval with Elizabeth Whittaker as a co-investigator. Elizabeth Whittaker conducted the interviews in both states. Elizabeth Whittaker and Marina Papic entered, coded and analysed the data. Wayne Warburton reviewed the literature and undertook supplementary data analyses. Wayne Warburton, Marina Papic and Elizabeth Whittaker wrote the paper.

Conflicts of Interest: The authors declare no conflict of interest.

\section{Appendix A. Interview Schedule for Mothers}

Thank-you for agreeing to speak with me today about your experiences of homelessness. As we outlined in the Participant Information and Consent Form, you can skip any questions you do not wish to answer, and everything you say will be confidential.

\section{Background information}

1. Let's start off by talking about you and your children. Could you tell me how old you are? And how old were you when you gave birth to your first child?

2. How many children have you given birth to? Are all of these children currently dependent on you (under your care)?

3. How old your children?

4. Are you of Aboriginal or Torres Strait Islander origin? 


\section{Homelessness history}

5. Thinking back now, did you experience homelessness before you were a mother? If so, how old were you?

6. Since having a child/children, what has led to you leaving previous houses you have had and becoming homeless? (both for the first time and if more than once, for each subsequent time).

7. How long have you been in your current homelessness state for?

8. What support or assistance would have stopped you from becoming homeless (kept your house) in the first place?

\section{Past housing experiences}

9. When you have previously lived in your own house, what has been good about it?

10. How important is it to have a home? What does it mean to you? What does it mean to your children?

11. What are some of the things that have made getting out of homelessness and back into housing difficult?

12. What stage are you at now with finding permanent housing?

Perceptions of, and experience with, [insert partner organisation]

13. How did you come to be involved with [insert partner organisation]?

a. How did you meet them?

b. Where were you living then?

c. What else was happening in your life at that time?

d. Had you been homeless for long at that point?

14. How long have you been visiting [insert partner organisation]?

15. What kind of support were you offered and what support did receive? (e.g., housing, health, employment, parenting guidance)

16. What are the good things about the [insert partner organisation] service? Were there any services at [insert partner organisation] that were particularly valuable for you?

17. What are the not-so-good things? Were there any services offered that you feel weren't very valuable for your situation?

18. If there anything they could improve on, or do faster that would have helped you to exit homelessness quicker?

19. Is the approach of workers at [insert partner organisation] different to other services you have contact with?

a. If so, in what way is it different?

20. Thinking more broadly now, are/were there any services you can think of that you feel would have helped you to exit homelessness but they didn't exist or they were too hard to access?

a. If so, find probe for more information on the type of services, whether it exists and specific barriers.

Assistance of services to exit homelessness

21. What things or assistance do you, or did you, use to get out of homelessness? Which were the most helpful?

22. What would have assisted you, or would have needed to have changed, for you to have found housing faster? 
Current housing (if successfully housed at time of interview)

23. How is life different for you since you moved into permanent housing? (Explore whether they are happy with the place; how it's impacted on their daily life routines, social issues etc.; how have the children responded).

24. Have you had any difficulties since you moved in?

a. If so, what were they and did they got sorted out? How did this happen?

25. What particular aspects of the service helped you move to a more stable housing situation?

26. Do you still have a relationship with your support workers at [insert partner organisation]?

a. If so, what kinds of things are you doing together now?

27. Are there supports or things you will need to assist you to stay in the house (specifics of support, length of time etc.)?

28. Do you see yourself staying here long term?

Exploration of young mothers (where applicable)

29. What are the unique issues for young mothers and their children that need to be taken into account?

30. How could the homelessness services better cater for young mothers?

Final comments

31. Do you have any final comments or suggestions to help improve homelessness services?

\section{Appendix B. Interview Schedule for Agency Staff}

Thank-you for agreeing to speak with me today about your work with homeless mothers at [partner organisation]. As we outlined in the Participant Information and Consent Form, you can skip any questions you do not wish to answer, and everything you say will be confidential.

Current position

1. Let's start off by talking about your current position. How long have you been in your role?

2. What does your role involve?

3. What services does the organisation offer to those experiencing homelessness?

a. Are all of these services offered to mothers and children? If not, which ones and why?

4. Can you briefly describe how clients are engaged into the service? Is there a referral or assessment process?

Strengths and weakness of the service

I want to ask you a couple of broad questions about your perceptions of the strengths and weaknesses of the service before we move on to more specific areas.

5. What do you think are the main strengths of the services you offer?

6. What do you think are the main weaknesses?

7. Have there been any service related challenges or barriers that the organisation has, or would like to, overcome?

Support services offered by the organisation

8. What kind of support services are offered to mothers and their children? (e.g., housing, health, employment, parenting guidance) 
9. What are the good things about the service? Are there any services that you feel are particularly valuable for mothers?

10. What are the not-so-good things? Are there any services offered that you feel aren't very valuable for mothers?

11. Are there are aspects that the service could improve on, or make the processes faster, to help mothers exit out of homelessness quicker?

12. To what extent currently do the services here address the needs of mothers and their children? (e.g., community participation, education/training, employment, mental and physical health, developmental delays).

Partnerships with other services

13. Are there needs that mothers and their children present with that the organisation cannot address internally and that require a referral off-site?

14. Have partnerships with agencies or other service providers been established, and for what purpose?

15. What would further strengthen these partnerships?

16. Do the partnerships help to meet/support the different needs of mothers and their children (e.g., severe mental health issues or Department of Justice clients)?

17. Are there any needs that mothers and their children present with that the organisation cannot address internally and where there is no known off-site service that can deal with the issue either?

Needs of mothers and their children

18. Has the organisation changed the types of services or support offered to mothers and their children over the time you have been here? (Prompt staff to expand briefly on any changes under relevant questions below).

19. In your experience, how do mother's needs change over time? (e.g., when they first present in crisis, after a few months of receiving support).
a. Housing
b. Economic (e.g., employment).
c. Physical and mental health.
d. Psychosocial e.g., relationship with family, social connectedness, education.

Young mothers

20. Thinking about young mothers, are there specific issues that they tend to present with? Are there certain service considerations you need to take into account when providing support to them?

\section{Final comments}

21. Have there been any unexpected outcomes of the support provided to mothers, whether they be positive or negative?

22. If you could change anything about the service to make it more effective for mothers and their children, what would you change?

Do you have any final comments or suggestions to help improve homelessness services in general?

\section{Appendix C. Background Information for the 14 Mothers}

M1 was 17 years old, had a two year old boy and had been homeless once following conflict at home. She was quickly housed in emergency housing through a Homelessness Support Service (HSS) and then in a subsidised private social housing rental run by a charitable organisation. 
M2 was 21 years old with an 18 months old girl. She had been homeless more than seven times and had stayed in emergency accommodation for DV victims, suggesting she may also have experienced DV. She had been homeless twice prior to her child being born and had very unstable housing during pregnancy - couch surfing, emergency accommodation and refuges. At the time of interview, she was in private rental in social housing run by a charitable organisation.

M3 was a 20 year old Aboriginal woman with two children (two years; four months) who left home due to family problems and wanting a better life for her child. After leaving a boarding house due to drugs and criminal activity, she contacted a HSS who quickly found suitable transitional accommodation.

M4 was 25 years old with a six year old boy. She had been homeless once, at age 19, leaving home due to conflict with her parents over her pregnancy. M4 immediately engaged with a HSS who arranged accommodation in a refuge and then transitional social housing run by a charitable organisation.

M5 was 21 years old, pregnant with her second child and had a three year old boy. She had been homeless many times and had also experienced DV. M5 had been running away from home since age five, started living away from home at 11 when she was disowned by her family and had a long history of couch surfing. M5 had her child at 18 and experienced further unstable accommodation before being forced into emergency housing to escape DV. Has contacted a HSS but was still couch surfing and sleeping rough at the time of interview.

M6 was a 21 year old Sudanese refugee with a two year old daughter who had experienced unstable housing five times. M6 had been evicted from a private rental whilst pregnant and a HSS had negotiated for her and her child to stay in the rental by establishing a repayment plan and assisting with rent.

M7 was 36 years old, had a 12 year old daughter and had experienced many periods of homelessness. M7 entered emergency housing at 17 to escape sexual and physical abuse, had unstable accommodation for several years and then social housing. M7 left social housing to escape DV and was placed in transitional housing by HSS.

M8 was 41 years old, had two children (13 and 10), had been homeless numerous times and had experienced DV. Her first unstable housing was at age 15 when her mother moved interstate but she did not (due to conflict). By age 16 M8 was sleeping rough and did this on and off for three years. Periods of unstable housing followed, including refuges to escape DV. More recently had contacted a HSS who arranged accommodation in a street motel and then transitional housing.

M9 was 23 years old with a seven month old boy and had been homeless three times. M9 had been orphaned in Somalia and put into a refugee camp before coming to Australia. M9 had another period of being homeless prior to having her child and later re-entered homelessness after leaving her husband with her child. M9 quickly engaged with a HSS, who arranged community housing.

M10 was 29 years old, had three children (six, five and nine months), had been homeless seven times or more and had experienced DV. M10 was first homeless when she separated from her first husband, couch surfing and using emergency hotels. M10 had to leave stable accommodation due to abusive visits from her ex-husband and experienced further housing instability. M10 approached a HSS, who arranged transitional housing.

M11 was 34 years old, had two children (four and one) and had experienced many periods of homelessness as well as DV. M11 left her own home due to DV but could not return fearing her violent ex-partner and his family. She and the children lived in caravans, tents, hotels and were also couch surfing. M11 then approached a HSS who found a transitional housing unit and then a suitable private rental.

M12 was a 31 year old Sudanese refugee with four children (14, 13, 6 and 4) who had experienced homelessness six times and had also experienced DV. M12 was in refugee camps before emigrating. In Australia M12 fled interstate to escape DV from her ex-husband, leaving all belongings behind. She approached a HSS who provided transitional accommodation and then further safe accommodation when she was found by her ex-husband. 
M13 was a 46 year old woman with four children $(25,22,7$ and 6$)$ who had experienced severe DV and more than seven periods of homelessness. M13 had fled her husband, living in a car and a caravan. Private rentals consistently failed due to sudden departures when she was found by her ex-husband. HSS arranged crisis accommodation for 3 months and at interview M13 was in a stable private rental.

M14 was a 25 year old Somalian refugee with a three month old daughter who had been homeless more than seven times. M14 left home at 22 because of conflict with her parents and was then in unstable housing - crisis accommodation, couch surfing and living in a car. Obtained transitional housing via a HSS soon after her baby was born.

\section{References}

1. Minnery, J.; Greenhalgh, E. Approaches to homelessness policy in Europe, the United States and Australia. J. Soc. Issues 2007, 63, 641-655. [CrossRef]

2. Australian Government. The Road Home: A National Approach to Reducing Homelessness; Department of Families, Housing, Community Services and Indigenous Affairs: Canberra, Australia, 2008.

3. Johnson, G.; Scutella, R.; Tseng, Y.; Wood, G. Entries and Exits from Homelessness: A Dynamic Analysis of the Relationship between Structural Conditions and Individual Characteristics; AHURI Final Report No. 248; Australian Housing and Urban Research Institute: Melbourne, Australia, 2015. Available online: http: //www.ahuri.edu.au/publications/projects/p53042 (accessed on 1 February2018).

4. Kuskoff, E.; Mallett, S. Young, Homeless and Raising a Child: A Review of Existing Approaches to Addressing the Needs of Young Australian Parents Experiencing Homelessness; Institute for Social Science Research, The University of Queensland: St Lucia, Australia, 2017.

5. Nirui, M.; Dudley, M.; Ferson, M. Health and wellbeing of the invisible: Homeless women with young children. Australas Psychiatry 2011, 19, 536. [CrossRef] [PubMed]

6. Australian Institute of Health and Welfare (AIHW). Specialist Homelessness Services: 2013-2014; Cat. No. HOU 276; AIHW: Canberra, Australia, 2014.

7. Australian Institute of Health and Welfare (AIHW). Specialist Homelessness Services Annual Report 2016-17; AIHW: Canberra, Australia, 2017. Available online: https://www.aihw.gov.au/reports/homelessnessservices/specialist-homelessness-services-2016-17/ contents/contents (accessed on 25 January 2018).

8. Henry, M.; Watt, R.; Rosenthal, L.; Shivji, A. The 2016 Annual Homeless Assessment Report (AHAR) to Congress; US Department of Housing and Urban Development Office of Community Planning and Development: Washington, DC, USA, 2016.

9. Bassuk, E.L.; De Candia, C.J.; Beach, C.A.; Berman, F. America's Youngest Outcasts: A Report Card on Child Homelessness; The National Center on Family Homelessness at American Institutes for Research: Waltham, MA, USA, 2014.

10. Vandentorren, S.; Le Méner, E.; Arnaud, A.; Jangal, C.; Caume, C.; Vuillermoz, C.; Martin Fernandez, J.; Lioret, S.; Roze, M.; Le Strat, Y.; et al. Characteristics and health of homeless families: The ENFAMS survey in the Paris region, France 2013. Eur. J. Public Health 2016, 26, 71-76. [CrossRef] [PubMed]

11. Toro, P.A. Toward an international understanding of homelessness. J. Soc. Issues 2007, 63, 461-481. [CrossRef]

12. Toro, P.A.; Lombardo, S.; Yapchai, C.J. Homelessness, Childhood; Kluwer: New York, NY, USA, 2003.

13. Thomas, K.A.; So, M. Lost in limbo: An exploratory study of homeless mothers' experiences and needs at emergency assistance hotels. Fam. Soc. 2016, 97, 120-131. [CrossRef]

14. Firdion, J.-M.; Marpsat, M. A research program on homelessness in France. J. Soc. Issues 2007, 63, 567-587. [CrossRef]

15. Grant, R.; Gracy, D.; Goldsmith, G.; Shapiro, A.; Redlener, I.E. Twenty-five years of child and family homelessness: Where are we now? Am. J. Public Health 2013, 103, E1-E10. [CrossRef] [PubMed]

16. Fitzpatrick, S.; Christian, J. Comparing homelessness research in the US and Britain. Int. J. Hous. Policy 2006, 6, 313-333. [CrossRef]

17. Guo, X.; Slesnick, N.; Fen, X. Housing and support services with homeless mothers: Benefits to mother and her children. Community Ment. Health J. 2016, 52, 73-83. [CrossRef] [PubMed]

18. Chambers, C.; Chiu, S.; Scott, A.N.; Tolomiczenko, G.; Redelmeier, D.A.; Levinson, W.; Hwang, D.A. Factors associated with poor mental health status among homeless women with and without dependent children. Community Ment. Health J. 2014, 50, 553-559. [CrossRef] [PubMed] 
19. Bassuk, E.L.; Beardslee, W.R. Depression in homeless mothers: Addressing an unrecognised public health issue. Am. J. Orthopsychiatry 2014, 84, 73-81. [CrossRef] [PubMed]

20. Zabkiewicz, D.M.; Patterson, M.; Wright, A. A cross sectional examination of the mental health of homeless mothers: Does the relationship between mothering and mental health vary by duration of homelessness? BMJ Open 2014, 4, e006174. [CrossRef] [PubMed]

21. Bassuk, E.L.; Richard, M.K.; Tsertsvadze, A. The prevalence of mental illness in homeless children: A systematic review and meta-analysis. J. Am. Acad. Child Adolesc. Psychiatry 2015, 54, 86-96. [CrossRef] [PubMed]

22. Bassuk, E.L.; Rosenberg, L. Psychosocial characteristics of homeless children and children with homes. Pediatrics 1990, 85, 257-261. [PubMed]

23. Mission, W. Homelessness and the Next Generation; Wesley Mission: Sydney, Australia, 2013.

24. Flatau, P.; Conroy, E.; Spooner, C.; Edwards, R.; Eardley, T.; Forbes, C. Lifetime and Intergenerational Experiences of Homelessness in Australia; Australian Housing and Urban Research Institute (AHURI) Final Report No 200; AHURI: Melbourne, Australia, 2013.

25. Bradley, C.; McGowan, J.; Michelson, D. How does homelessness affect parenting behaviour? A systematic critical review and thematic synthesis of qualitative research. Clin. Child Fam. Psychol. 2018, 21, 94-108. [CrossRef] [PubMed]

26. Hulse, K.; Kolar, V. 'The Right to Belong': Family Homelessness and Citizenship; Swinburne University of Technology and Hanover Welfare Services: Melbourne, Australia, 2009.

27. Institute for Children and Poverty. Children Having Children: Teen Pregnancy and Homelessness in New York City; Homes for the Homeless: New York, NY, USA, 2003.

28. Narendorf, S.C.; Williams Jennings, S.; Santa Maria, D. Parenting and homeless: Profiles of young adult mothers and fathers in unstable housing situations. Fam. Soc. 2016, 97, 200-211. [CrossRef]

29. McArthur, M.; Winkworth, G. Give them a break: How stigma impacts on younger mothers accessing early and supportive help in Australia. Br. J. Soc. Work 2017, 1-19. [CrossRef]

30. Office of the Prime Minister of Australia. COAG Summit to Address Violence against Women and Their Children; Media Release by the Office of the Prime Minister of Australia: Canberra, Australia, 17 October 2016. Available online: https:/ / www.pm.gov.au/media/coag-summit-address-violence-against-women-andtheir-children (accessed on 25 January 2018).

31. Maslow, A.H. A theory of human motivation. Psychol. Rev. 1943, 50, 370-396. [CrossRef] 